\title{
Attitudes towards nutritional supplement use amongst adult gymnasium users in Johannesburg North
}

X Mc Creanor, Bed FET, BA (Hons) Human Movement Science, MPhil Sport Science; Y Coopoo, DPhil, FACSM and G Gabriels, PhD

Department of Sport and Movement Studies, Faculty of Health Science, University of Johannesburg, Gauteng, South Africa

Corresponding author: Y Coopoo (yogac@uj.ac.za)

Background: Nutritional supplements refer to a product ingested to increase the nutritional content of a normal diet, to fill a dietary need and/or presumed deficiency. The usage and popularity of nutritional supplements, however, raises concerns from a health benefit and risk perspective. In South Africa, there is currently no adequate regulatory framework of enforcement for nutritional supplement products and undeclared constituents by the statutory body, the Medicines Control Council (MCC). Education awareness programmes by organisations that should take consumer protection and the general public health and wellness as a right, needs to be improved.

Objectives: To investigate the attitudes toward nutritional supplements by adult gym users from commercial gymnasiums in the Johannesburg North region of South Africa.

Methods: A cross-sectional quantitative design, using a selfadministered questionnaire was applied to 364 recruited study participants who attended commercial gymnasiums in Johannesburg North.

Results: One hundred and fifty users (41\%) claimed that they 'always' read the information about the nutritional values, benefits, and side effects of the supplements on the labels prior to use. Three hundred and three users ( $83 \%$ ) indicated that the number of users of nutritional supplements in gymnasiums is on the increase. Two hundred and seventy-three (75\%) of main information sources for nutritional supplements may be found on the internet, while $292(80 \%)$ indicated the need for gymnasiums to provide educational programmes pertaining to nutritional supplement consumption.

Conclusion: Gymnasium users are aware of the increase in nutritional supplement use in commercial gymnasiums. Many of the users were unaware of the potential mislabelling and health concerns regarding these supplements. Therefore there is a need for improved nutritional supplement education programmes and diligence at multiple levels.

Keywords: proteins, vitamins, peer pressure, unregulated, information sources, education

\section{S Afr J Sports Med 2017;29:1-5. DOI: 10.17159/2078-516X/2017/v29i0a1387}

Concern has been raised in the South African health industry regarding the use of unregulated nutritional supplementation in sport. ${ }^{[1]}$ While manufacturers use marketing to promote the value of supplements towards the maintenance of good health, the consumer's focus should be more on awareness, education, and the improvement of health. ${ }^{[1]}$ Moreover, a study conducted by Block et al. ${ }^{[2]}$ found that users who consumed a wide selection of nutritional supplements on a daily basis were more prone to have optimal concentrations of chronic disease-related biomarkers, and be less prone to suboptimal nutrient concentrations, high blood pressure and diabetes when compared to non-nutritional supplement users. ${ }^{[2]}$ The study by van der Merwe and Grobbelaar tested for testosterone and nandrolone prohormones, various ephedrines and caffeine in supplements.[3] They concluded that $18(60 \%)$ contained non-prohibited supplements, and $12(40 \%)$ of the supplements tested positive for numerous prohibited substances. ${ }^{[3]}$ The authors state that these contaminated supplements pose a major concern for the health of their users, including the possibility of allergies to banned substances. ${ }^{[3]}$ Similar work by Geyer et al. provides evidence for the health risks from these supplements. ${ }^{[4]}$ Out of the 634 samples analysed in this study, $15 \%$ contained banned substances not declared on the label.. ${ }^{[4]}$ In South Africa, users of such supplements may be in contravention of the South African Institute for Drug-Free Sport's regulations (SAIDS). SAIDS' 2014 Annual Report states that it is the statutory body that promotes participation in sport which is free from the use of prohibited performance enhancing substances or methods that artificially enhance performance. ${ }^{[3]}$ Linked to this statement is the study by Morrison et al. which indicated that $85 \%$ of participants consumed supplements ethically. ${ }^{[5]}$ In this study, the consumption categories and usage of at least five times per week were multivitamins (45\%), protein shakes $(42 \%)$, vitamin C (35\%) and vitamin E (23\%). ${ }^{[5]}$ This present study investigated the attitudes towards nutritional supplements in commercial gymnasium patrons in the Johannesburg North region with respect to their use, acquisition of information and knowledge of the supplement, their reasons for going to a gymnasium, attitudes towards the supplement's consumption, and types of products consumed.

\section{Methods}

The study's design is a quantitative cross-sectional design. A self-administered questionnaire was approved by the University of Johannesburg, Faculty of Health Sciences Research Ethics Committee (REC-01-144-2015). It was adapted and validated, based on a study undertaken by Gradidge. ${ }^{[6]}$

The study was conducted in the Johannesburg North region at five selected reputable gymnasiums, and only focused on adult gym members. The sample was computed, based on the work of Sekaran ${ }^{[7]}$ was obtained by a systematic convenience sampling method, consisting of a total of 364 participants aged between 18-49 years who attend a gymnasium two or more times per week. Prior to the commencement of completing the questionnaire, information about the study, anonymity and the option to refrain from answering the questionnaire if they so wished. Aspects of the questionnaire made use of a 4 point 
Likert scale that required participants to select from the range 'strongly agree' to 'strongly disagree', to specific statements. The principal investigator was available to provide clarity regarding the questions to the study's participants, if necessary.

Data for the study were manually transcribed and independently validated using the Windows-based Microsoft () Office Excel 2003 SP 1 (Excel (C) 1985-2003 Microsoft Corporation). The Statistical Package for the Social Sciences (SPSS Inc. version 16) was used to calculate the descriptive statistics.

\section{Results}

\section{Demographic data}

Gymnasium users in the Johannesburg North area ranged from between 18-49 years (mean 27 years) of age. Of the total of 364 participants, 205 (56\%) were male and 159 (44\%) were female. Two hundred and nineteen $(60 \%)$ of the participants indicated that they started using nutritional supplements between 13 -18 years (high school), 84 (23\%) started at $10-12$ years (primary school), while $62(17 \%)$ were over 18 years old. These results indicate how early in life supplements were used by adolescents.

\section{Nutritional consumption assessment}

Three hundred and three (83\%) of the participants indicated that users of nutritional supplements in gymnasiums is on the increase. Their perception of increase usage was by observation while training at gymnasiums. Two hundred and seventy $(74 \%)$ of respondents believe that gymnasium users are pressurised to use nutritional supplements, as their training friends were taking supplements to improve performance and perceived recovery from training. This subtle peer pressure caused them to follow the usage pattern of their friends as they felt that they were not going to benefit as much as their peers did. Two hundred and seventy-three respondents $(75 \%)$ indicated that they were aware of supplements that are prohibited by the World Anti-Doping Agency, and 91 (25\%) indicated that they had no knowledge of prohibited supplements.

\section{Sources of nutritional supplement information acquisition}

Table 1 shows the categories of information acquisition for nutritional supplements for which the participants had the choice of multiple options.

The findings in Table 1 show that the main sources of information regarding nutritional supplements, in order of priority from the respondents, the internet $(75 \%)$, pharmacists $(67 \%)$, and books $(66 \%)$. The provision of information on supplements which was least accepted by the respondents was information from parents $(38 \%)$, siblings $(37 \%)$, physicians $(36 \%)$, and biokineticists $(34 \%)$.

\section{Reasons for going to the gymnasium}

Fig. 1 illustrates that, according to the respondents, the main reason for attending gymnasiums is to gain muscle (56\%). Other reasons are to stay healthy (36\%) and for crossfit training purposes $(36 \%)$ respectively. Swimming (30\%), spiritual motives $(30 \%)$ and aerobic exercise were lesser reasons for going to the gymnasium.

\section{Attitudes towards nutritional supplement consumption by participants}

Table 2 shows that the main reason why respondents consumed nutritional supplements was to be healthier $(82 \%)$, and the least likely reason was as a result of peer pressure (54\%).

Table 3 shows the nutritional supplements of choice by the respondents are proteins $(84 \%)$, carbohydrates $(72 \%)$, and vitamins $(71 \%)$. The supplements consumed to a lesser extent

Table 1. Sources of information regarding nutritional supplements

\begin{tabular}{lccc}
\hline \multicolumn{1}{c}{ Source } & $\mathbf{n}$ & Yes (\%) & No (\%) \\
\hline Internet & 370 & 75 & 25 \\
Pharmacists & 371 & 67 & 33 \\
Books & 370 & 66 & 34 \\
Personal trainer & 372 & 59 & 41 \\
Newspapers & 372 & 59 & 41 \\
Magazines & 372 & 57 & 43 \\
Friend/Training Partner & 373 & 48 & 52 \\
Journals & 370 & 47 & 53 \\
Representatives from & 370 & 47 & 54 \\
nutritional companies & & 45 & 55 \\
Information brochures & 369 & 38 & 63 \\
Parents & 371 & 37 & 63 \\
Siblings & 370 & 36 & 64 \\
Physicians & 371 & 34 & 66 \\
Biokineticists & 371 & & \\
\hline$n=$ total number of respondents, $(\%)$ & percentage of respondents
\end{tabular}

$n=$ total number of respondents, $(\%)=$ percentage of respondents 
by the respondents are phedra-cut thermogenic aids (35\%) BCAA (34\%) and L-Glutamine (33\%).

\section{Information on labels of products}

One hundred and forty-nine (41\%) of the respondents ( $n=362)$,

Table 2. Reasons why participants consume nutritional supplements

\begin{tabular}{|c|c|c|c|}
\hline Reason & $\mathbf{n}$ & Yes (\%) & No $(\%)$ \\
\hline To be healthier & 219 & 82 & 18 \\
\hline $\begin{array}{l}\text { Assists me in coping with the stresses of } \\
\text { muscle gains in the gymnasium }\end{array}$ & 221 & 79 & 21 \\
\hline $\begin{array}{l}\text { Helps to improve the way I perform in } \\
\text { the gymnasium }\end{array}$ & 220 & 73 & 27 \\
\hline Helps me to reach my personal goals & 220 & 70 & 30 \\
\hline $\begin{array}{l}\text { Helps to reduce food cravings in order } \\
\text { to decrease my body weight }\end{array}$ & 221 & 62 & 38 \\
\hline I feel pressured by my peers & 220 & 54 & 46 \\
\hline
\end{tabular}

$n=$ total number of respondents, $(\%)=$ percentage of respondents

Table 3. Nutritional supplement consumption by gymnasium users

\begin{tabular}{lccc}
\hline \multicolumn{1}{c}{ Supplement } & n & Yes (\%) & No (\%) \\
\hline $\begin{array}{l}\text { Protein supplements (e.g. Whey } \\
\text { protein) }\end{array}$ & 366 & 84 & 16 \\
$\begin{array}{l}\text { Carbohydrate supplements } \\
\text { (e.g. Energade, Powerade) }\end{array}$ & 367 & 72 & 28 \\
$\begin{array}{l}\text { Vitamins (A, B, B12, C, D and E) } \\
\text { Creatine supplements }\end{array}$ & 365 & 71 & 29 \\
$\begin{array}{l}\text { (e.g. Creatine monohydrate) } \\
\text { Caffeine (e.g. Redbull, Guarana) }\end{array}$ & 367 & 67 & 33 \\
$\begin{array}{l}\text { Fish oil (e.g. Omega 3 tablets) } \\
\text { CLA (Conjugated linoleic acid) }\end{array}$ & 367 & 59 & 41 \\
weight loss supplements & 366 & 36 & 63 \\
Phedra-cut thermogenic aid & 365 & 35 & 65 \\
Branched-chain amino acids (BCAA) & 366 & 34 & 66 \\
L-Glutamine & 365 & 33 & 67 \\
\hline
\end{tabular}

$n=$ total number of respondents, $(\%)=$ percentage of respondents indicated that they 'always' read the nutritional value, benefits and side effects of the supplement on the labels before they used the supplements. One hundred and seventy-four (48\%) indicated that they do this 'sometimes', and $40(11 \%)$ indicated that they 'never' read the information on the labels.

\section{Summary of attitudes towards the consumption of supplements in the gymnasium}

Table 4 shows that $80 \%$ of the respondents indicated a need for gymnasiums to provide educational programmes pertaining to the use of nutritional supplements in gymnasiums, $73 \%$ of respondents indicated that gymnasium participants use supplements to enhance performance, and $70 \%$ of the respondents felt that there has not been sufficient reporting by the media with respect to the use of nutritional supplements.

\section{Discussion}

The work of Gabriels et al. shows that the nutritional supplement market remained robust throughout the global recessionary period of 2008 to 2009, as well as tremendous growth. ${ }^{[1]}$ The gymnasium users in this study were aged 18 to 49-years-old. The study by Fitzgibbon et al. showed that teenagers' body-image discrepancy and social influences were among reasons for the use of supplements. ${ }^{\left[{ }^{[]}\right.}$The above factors point to the impact of market exposure on the introduction to consumption of nutritional supplements. This concurs with this present study which shows that eighty-four $(23 \%)$ of the gymnasium participants who first used supplements were between the ages of 10 to 12 years. This early exposure to supplements indicates an association of steroid use, concomitant with the use of nutritional supplements. ${ }^{[9,10,11]}$ The study by Van der Walt and Coopoo ${ }^{[12]}$ concluded that coaches defended the practice of supplement use, as they stated that it helped to build relationships of trust with their athletes. Coaches may thus contribute to the culture of why a large proportion of respondents $(74 \%)$ in this study believe that they are pressurised into using nutritional supplements. ${ }^{[12]}$ This pressure may have a causal impact regarding the 'attitude profile' highlighted in Table 4.

Table 4. Attitudes regarding supplement consumption in gymnasiums

\begin{tabular}{|c|c|c|}
\hline Supplement & $\mathbf{n}$ & $(\%)^{*}$ \\
\hline Gymnasiums should offer educational programmes for gymnasium users on the use of supplements in gymnasiums & 371 & 80 \\
\hline There are too many gym users using supplements to enhance their performance in gymnasiums & 372 & 73 \\
\hline The use of nutritional supplements by gymnasium users has not been sufficiently reported in the media & 372 & 70 \\
\hline Many of my friends think it is acceptable to use nutritional supplements & 367 & 60 \\
\hline There is a problem with nutritional supplement use in my gymnasium & 370 & 60 \\
\hline I am sometimes tempted to use performance enhancing supplements & 365 & 58 \\
\hline The use of performance enhancing supplements and nutritional supplements has increased in the last five years & 371 & 43 \\
\hline I would never consider the use of any nutritional supplementation & 372 & 40 \\
\hline I think it is always wrong to use nutritional supplements for gym purposes & 372 & 34 \\
\hline $\begin{array}{l}\text { Some think gymnasium participants who want to reach their goals have to sometimes use performance enhancing } \\
\text { supplements }\end{array}$ & 372 & 32 \\
\hline I do not think it is fair to use performance enhancing supplements & 370 & 16 \\
\hline $\begin{array}{l}\text { If I do not take nutritional supplements, I will not be able to succeed in my performance because everyone else in the } \\
\text { gym is using supplements }\end{array}$ & 369 & 5 \\
\hline
\end{tabular}
$n=$ total number of respondents, $(\%)^{*}=$ percentage of respondents who strongly agreelagree 
The main source of information on nutritional supplements for gymnasium participants in this study was the internet $(75 \%)$. This is in contrast to the findings of Van der Walt and Coopoo which identified pharmacists to be the main source of this information. ${ }^{[12]}$ The age group sampled in the study by Van der Walt and Coopoo, however, was the parents of high school children, which may explain the difference in the study findings.

The results in Table 3 show that the nutritional supplements of choice by the respondents were proteins (84\%), carbohydrates $(72 \%)$, and vitamins $(71 \%)$. This compares to similar consumption patterns found in the work of Froiland et al., ${ }^{[13]}$ showing vitamin and mineral supplements as the third largest over-the-counter supplement category. ${ }^{[13]}$ One of the reasons presented in this study as to why the gymnasium respondents $(70 \%)$ use protein supplements was to gain muscle thereby reaching one of their personal training goals. However, these consumers were unaware of the potential health risks of taking these supplements as pointed out by Mottram ${ }^{[14]}$ and Mueller et al. ${ }^{[15]}$, who stated that animal and plant sources may also contain toxic chemicals. Also, the excessive consumption of protein shakes can produce toxic effects that may lead to potential health problems, such as kidney disease, water retention and high levels of ketones in the body ${ }^{[14,15]}$ Gabriels et al. state that performance enhancing supplements may cause health problems due to contamination and/or adulteration. ${ }^{[1]}$ These studies are supported by evidence that the potential health risks are not necessarily apparent due to the non-declaration of all product ingredients on the label and associated warnings and side effects. ${ }^{[4]}$ In this scenario, consumers are at risk, regardless of whether or not they read the labels before using the supplements. In these authors' opinion, additional protein intake is unnecessary if a balanced diet is followed.

Furthermore, the evidence shows that there is poor knowledge regarding nutritional supplements and/or there is a need for an 'attitude' change towards meaningful awareness requirements with respect to intelligent nutritional supplement usage. ${ }^{[6]}$ Nutritional supplement usage begins in many cases at a young age (10 to 12 years), and continues into adulthood. This study's findings point to the nutritional supplement industry sector which is unregulated and which may lead to a potential negative impact on the consumer's health. There are many schools in Gauteng that have a supplement shop on campus. ${ }^{[16]}$ This sends mixed messages to school athletes. Education is one of the ways to inform the public about the risks and benefits of supplement use.

\section{Conclusion}

Johannesburg North's gymnasium participants are aware of the increase in nutritional supplement usage in gymnasiums. The most popular supplement used by gymnasium participants in this study was protein, for muscle gain. This may be the first indication of muscle dysmorphia. Respondents cited their main source of information to be the internet and that few healthcare and wellness professionals are consulted for advice on nutritional supplements. This study shows that there is a deficiency in the knowledge of the participants with regard to most nutritional supplements. A health concern is that more than half of the participants in the study did not read product labels. The requirement for education and awareness programmes and information campaigns on the health risks of supplement use should be implemented or improved.

\section{Study limitations}

The main limitation in all of the questionnaires was poor memory and truthfulness.

\section{Recommendations}

Educating gymnasium users and the general public about the health risks involved in taking nutritional supplements is essential, and ensuring that all consumers seek appropriate professional advice before consuming supplements. Educational programmes on nutritional supplements and their potential health risks should be available in primary and high schools, and at tertiary institutions to assist potential gymnasium participants and the guardians of minors. Gymnasiums should also offer educational classes to their patrons that focus on the moral and ethical use of nutritional supplements.

\section{Future research}

Similar gymnasium studies, using the self-administered questionnaire used in this study should be conducted throughout South Africa. Specific male and female assessments of 'attitudes' towards nutritional supplement use by adult participants at gymnasiums would be useful. This would assist in standardising the 'attitudes' towards supplement use at gymnasiums across the country.

\section{References}

1. Gabriels G, Lambert M, Smith P. Information on nutritional supplement labels: time for legislation? South Afr J Clin Nutr 2012; 25: 22-26[https://doi.org/10.1080/16070658.2012.11734398]

2. Block G, Jensen CD, Norkus EP, et al. Usage patterns, health, and nutritional status of long-term multiple dietary supplement users: a cross-sectional study, Nutr J 2007; 6: 30 [doi.org/10.1186/1475-2891-6-30]

3. Van der Merwe PJ, Grobbelaar E. Inadvertent doping through nutritional supplements is a reality: original research article. $S$ Afr J Sports Med 2004; 16 [http://dx.doi.org/10.17159/2078516x/2004/V16i2A180]

4. Geyer H, Parr MK, Mareck U,et al.. Analysis of non-hormonal nutritional supplements for anabolic-androgenic steroids results of an international study. Int J Sports Med 2004; 25: 124 129 [doi:10.1055/s-2004-819955]

5. Morrison L, Gizis F, Shorter K. Prevalent use of dietary supplements among people who exercise at commercial gym. Int J Sport Nutr Exerc Metab 2004; 14: 481-488 [doi: 10.1123/ijsnem 14.4.481]

6. Gradidge PJ-L. The use of performance enhancing substances by adolescent male athletes in selected Johannesburg boys' high schools. Unpublished Masters thesis. University of Witwatersrand, $2010 . \quad$ Retrieve http://wiredspace.wits.ac.za/handle/10539/9001 (accessed 15 th $^{\text {h }}$ June 2017)

7. Sekaran U. Research methods for business: A skill-building approach 2nded. New York: John Wiley \& Sons, 1992: 253 
8. Fitzgibbon ML, Blackman LR, Avellone ME. The relationship between body image discrepancy and body mass index across ethnic groups. Obes Res 2000; 8: 582-589. [doi: 10.1038/oby.2000.75]

9. Dodge TL, Jaccard JJ. The effect of high school sport participation on the use of performance-enhancing substances in youth adulthood. J Adolesc Health 2006; 39: 367-373 [doi: 10.1016/j.jadohealth.2005.12.025]

10. Lucidi F, Zelli A, Mallia L, et al. The social-cognitive mechanisms regulating adolescents' use of doping substances. J Sports Sci 2008; 26: 447-456. [doi:10.1080/02640410701579370]

11. Mazanov J, Petróczi A, Bingham J, et al.. Towards an empirical model of performance enhancing supplement use: a pilot study among high performance UK athletes. J Sci Med Sport 2008;11:185-190 [doi.org/10.1016/j.jsams.2007.01.003]
12. Van der Walt V, Coopoo Y. A survey of the attitudes and knowledge of parents of high school children on the East Rand on the usage of nutritional supplements. S Afr J Sports Med 2016; 28: 74-78. [https://doi org/:10.17159/2078516/2016/v28i3a1674]

13. Froiland K, Koszewski W, Hingst J, et al.. Nutritional supplement use among college athletes and their sources of information.Int J Sports Nutri Exerc Metab 2004; 14: 104-120 [ https://doi.org/10.1123/ijsnem.14.1.104]

14. Mottram DR. Doping control in sport. In: Drugs in Sport. $4^{\text {th }}$ ed. London: Taylor \& Francis, 2005; 1-31.

15. Mueller K, Hingst J. The Athlete's Guide to Sports Supplements. Champaign, Ill.: Human Kinetics. 2013.

16. Gradidge P, Coopoo Y, Constantinou D. Prevalence of performance-enhancing substance use by Johannesburg male adolescents involved in competitive high school sports. Arch Exerc Health Dis 2011; 2: 114-119. [doi: 10.5628/aehd.v2i2.102] 